\title{
Demand-Side Policy: Global Evidence Base and Implementation Patterns
}

\author{
Author Details \\ Author: Dr. Peter Warren \\ Affiliation: University College London (UCL) \\ Address: School of Public Policy, 29/31 Tavistock Square, London, WC1H 9QU, UK \\ Email: peter.warren@ucl.ac.uk
}

\section{Abstract}

Demand-side management (DSM) policy refers to government policies for managing energy consumption in order to meet environmental and energy security objectives. The broader term of DSM encompasses energy efficiency, demand response, and on-site generation and storage. A comprehensive meta-evaluation of the global evidence base for demand-side policy is lacking in the literature, and this paper contributes to filling this research gap. The paper focuses on the quality of the evidence base and policy implementation patterns, and identifies 30 countries and 36 sub-national states across six continents that have implemented DSM policies and produced high-quality ex-post evaluations of those policies. The 690 high quality evaluations are primarily conducted by industry rather than by governments or academia. The results show that twelve types of individual DSM policy and nine DSM policy packages have been implemented and evaluated, and that carbon emissions reduction is the primary driver for DSM policies. The evidence base is greatest in the USA, UK, California, France and China, and alternative utility business models (such as performance targets and decoupling policies), information campaigns, loans and subsidies, utility obligations, and performance standards are the most commonly implemented and evaluated policies. This paper argues that demand-side policy will 
play an increasingly important role as a complement to low carbon activities on the supply-side in the transition to a more environmentally sustainable energy system.

\section{Key Words}

Demand-side management policy; energy efficiency policy; demand response; policy evaluation; systematic review; policy implementation

\section{Introduction}

Demand-side management (DSM) refers to actions and programmes on the demand-side of energy meters that seek to manage energy demand in order to meet various policy objectives, such as carbon emissions reduction, energy security and fuel poverty reduction (Warren, 2014a). DSM includes energy efficiency, demand response, on-site generation and on-site storage on the demand-side of meters (Warren, 2014a), thus excluding actions undertaken at the distribution, transmission or generation levels. Although the policy side of DSM has received attention in the academic literature, the volume of studies is masked by the much greater focus on (non-government-stimulated) energy utility programmes, technological trials and modelling studies of the future potential of specific aspects of the demand-side, such as demand response or energy efficiency. Much of the research has focussed on North American experiences since the energy crises of the 1970s and European experiences since the 1990s when the environmental agenda became more prominent. More recently in the 2000s and 2010s, there has been an increase in studies from east-Asia, particularly China. 
A global meta-evaluation of the evidence base for DSM policy is lacking in the literature, and this paper presents some of the results of a four-year project to systematically review the global evidence base for DSM policy. This paper focuses on answering the following research question in order to contribute towards filling the research gap:

What DSM policies have been implemented around the world with high-quality documented evaluations?

Section two critically reviews the policy process, drawing on research from political science. One of the key aims of the section is to fill a gap in identifying where the theory and practice of the policy process in energy policy may or may not match up. Section three then provides a conceptual framework for understanding the policy side of DSM, particularly in terms of policy evaluation. Section four outlines the methodology for the research, which is based on developing new techniques for applying systematic reviews in the energy policy field. Section five then discusses the results, which are split into: overall policy implementation patterns, policy packages, temporal patterns and the primary policy objectives for implementing DSM policies. Section six provides the overall conclusions for the research question.

\section{The Policy Process}

Policy research can be divided into examining the policy process, policy design, policy implementation and policy evaluation (Hill, 2009; Nagel, 2002). In political science, there is a vast literature on policy evaluation and in the Stages Model of the policy process, outlined in 
Hogwood and Gunn (1984, p. 4), policy evaluation is the eighth stage in a nine-stage process, as shown below:

1. Deciding to decide

2. Deciding how to decide

3. Issue definition

4. Forecasting

5. Setting objectives and priorities

6. Options analysis

7. Policy implementation, monitoring and control

8. Evaluation and review

9. Policy maintenance, succession and termination

However, some authors, such as Hill (2009, p. 143) and John (1998, p. 196) have criticised the Stages Model for being overly simplistic of how policy works in practice. Hill (2009) describes evaluating policy as a function of a controlled trial method (with a control group) or reaching desired states (such as a reduction in air pollution) (pp. 279-280). Nevertheless, in contrast to Hill (2009), Nagel (2002) defines policy evaluation as: “...evaluating alternative public policies, as contrasted to describing them or explaining why they exist" (p. 133). Nagel (2002) highlights a number of criteria for evaluating government policy: equity, validity, importance, usefulness, originality and feasibility (p. 134-136). He extends this to include the following broad terms: effectiveness, efficiency, public participation, predictable and procedural due process, and political feasibility (p. 92). 
What is common in all three of the examples (Hogwood and Gunn, 1984; Hill, 2009 and John, 1998 ) is that there is an inherent acceptance that policy evaluation is an important part of the policy process. However, what they do not acknowledge is that policy evaluation is not as common in practice (particularly in some fields, such as energy policy) as would be expected in theory. As this paper demonstrates, thousands of DSM policies have been implemented around the world, but only 690 high quality evaluations have been produced, the majority of which were conducted by industry rather than governments or academia.

Governments have a number of 'tools' at their disposal for the implementation of policies: 'topdown', which includes law and regulation; 'internal to the state', which includes bureaucracy and public management; and 'non-standard', which includes information, persuasion, deliberation, networks and governance (John, 2011, p. 10). Historically, much of the focus in energy policy implementation has been on the role of tools that are top-down, such as regulations, or internal to the state, such as the use of existing and new institutions (John, 2011). However, there has been a growing interest in the role that non-standard tools, such as persuasion and deliberation, can play in addition to traditional methods. Despite the usefulness of John (2011)'s conceptual framework of policy 'tools', one criticism of its application to energy policy is through the use of the label 'non-standard' for some 'tools' that have been used as 'standard' policy approaches in the past, such as information campaigns and stakeholder networks.

Increased attention is being given to the role of information, persuasion and deliberation in policy implementation. For example, the UK Government set up a Behavioural Insights Team within its Cabinet Office in 2010 with the aim of applying the 'nudge' theory to areas of policy, such as energy efficiency, health, tax, consumer data access and organ donation (Behavioural 
Insights Team Annual Update 2010-2011 report). The UK was the first country to set up a dedicated team within Government to apply behavioural theories to public policy (however, the Behavioural Insights Team was privatised in 2014 to become independent of government). The 'nudge' theory, developed by Thaler and Sunstein (2008), argues against the traditional neoclassical economics view that people always make decisions rationally under conditions of being fully informed through access to perfect information. Instead, it states that people make predictable mistakes based on their experiences (heuristics) and social interactions. Dawnay and Shah (2011) (in Dietz et al., 2011, pp. 74-75) expand this notion by listing key influences on people's decisions:

- Other people's behaviour matters

- Habits are important

- People are motivated 'to do the right thing'

- People's self-expectations influence how they behave

- People are loss-averse

- People are bad at computation

- People need to feel involved

The influence of peers, experiences, habits, social norms and the availability of (and ability to process) information are key characteristics of human behaviour (Strachan and Warren, 2011) that need to be considered in the design and implementation of policies to encourage consumer engagement with DSM. As Gellings and Chamberlin (1993) note: "Research indicates energyuse behaviour and belief are resistant to change. Successful approaches to the consumer seem to be personal, possibly emotional, specific and narrow with concrete suggestions" (p. 340). 
Hence, the traditional incorporation of rational choice theory in policy development is beginning to be replaced with a holistic policy framework that incorporates the importance of information, persuasion and deliberation. These arguments have particular relevance to the residential sector, but can similarly be applied to the non-residential sector. For example, competitors may represent credible 'peers' and hence an organisation is more likely to adopt certain measures if their competitors have done so (Gellings and Chamberlin, 1993, p. 334). A comprehensive review by Sorrell (2015) highlights that governments are increasingly using ideas from behavioural economics and social psychology to inform policy design for energy efficiency, though he argues that an effective policy approach would draw upon all disciplinary perspectives.

Hogwood and Gunn (1984)'s Stages Model is useful in breaking down the policy process into sub-stages beyond simply design, implementation and evaluation. However, there are three important criticisms of the conceptual model: firstly, evaluation should take place at all stages of the policy process; secondly, post-policy evaluations should be used to inform the design of future policies; and thirdly, there is an inherent assumption that post-policy evaluations are actually conducted in practice. The next section applies these discussions to DSM policy.

\section{Demand-Side Policy}

DSM policy refers to all types of demand-side policies. However, in practice, much of the literature has focused on energy efficiency policy rather than policies for demand response, onsite generation or on-site storage. Figure 1 summarises the main types of demand-side policy, broken down into those that are market-based, regulatory, information-based or fiscal. This 
draws parallels to other categorisations in the literature, such as Grubb (2014), which categorises policies into: information-based tools, regulatory standards and financial incentives (p. 165). However, such categories have focused specifically on energy efficiency rather than the wider concept of DSM. A temporal critique of DSM definitions and categorisations since the 1970s is provided in Warren (2014a). Thus, figure 1 aims to provide a broad, but comprehensive, overview of the range of demand-side policy types that have been implemented by governments in the past. As such, it is not a definition of DSM but a categorisation of DSM policy types. The figure is developed from the separate 'Systematic Review' reference list provided at the end of the paper, which is discussed in section four.

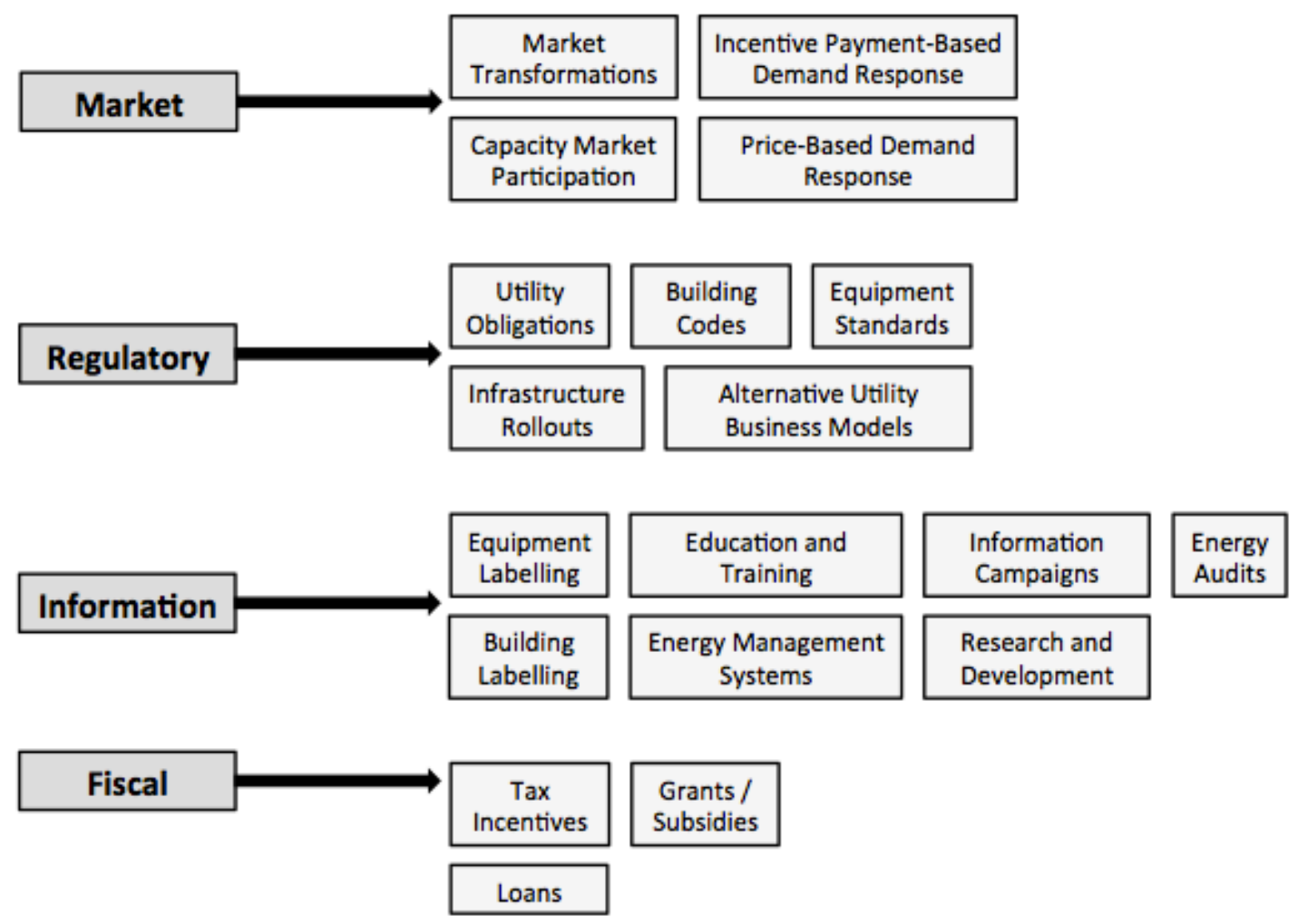


Figure 1: the main categories of demand-side management (DSM) policy

Each of the policies in figure 1 can be broken down further into specific policies. For example, incentive payment-based demand response (IPBDR) refers to incentives, such as direct financial payments, given to consumers to reduce energy consumption during peak periods. Specific types of IPBDR include the provision of regulatory and market frameworks to allow direct load control, interruptible/curtailable programmes, demand bidding, ancillary services market provision, emergency demand response and relieving network constraints in specific locations (Albadi and El-Saadany, 2008). However, due to the global scale of this research project, the level of IPBDR is examined rather than specific policy sub-types, as the aim was to be as comprehensive as possible across all types of DSM within the resource constraints of the research. As discussed in section six, further research with greater resources should utilise the same methodological approach (outlined in section four) and examine the specific policy level, either within a specific category of DSM (energy efficiency, demand response or on-site generation/storage) or across the range of categories.

Evaluations of DSM policy are typically ex-ante, ex-post or a combination of both types. Ex-ante appraisals look at the expected effects of a policy (for example, 'deemed' energy savings and engineering estimates), whereas ex-post evaluations look at the empirical results of a policy (for example, measuring the actual impacts from monitoring studies) (Fischer, 1995). Ex-ante approaches can only estimate in advance the potential effectiveness of a policy but are much less resource-intensive to carry out. In contrast, ex-post approaches require the measurement and monitoring of policy impacts, which increases the reliability of the estimates of the impacts but are more resource-intensive to carry out. Combined approaches are useful where ex-post 
evaluations feed into improving the accuracy of modelling tools in ex-ante appraisals (Mundaca and Neij, 2010). However, as Stern and Vantzis (2014) show, evaluators in North America tend to undertake ex-post approaches, whereas in Europe, evaluators more commonly conduct exante approaches. Stern and Vantzis (2014) argue that Europe can learn from the North American experiences in conducting ex-post evaluations to improve the reliability of policy evaluations.

In addition to the type of evaluation, who evaluates the policy is similarly important. Ex-post evaluations undertaken by governments can be politically damaging if they show a policy to have failed, and it is possible that biases could exist in such evaluations. As a result, there is arguably a role for independent third parties to undertake evaluations of DSM policies using a combination of ex-ante and ex-post methods.

In calculating energy savings in all types of DSM policy evaluation, it is crucial to consider the factors summarised in figure 2 , which represents the theoretically 'perfect' evaluation under conditions of abundant available resources. In practice, due to resource constraints, trade-offs are made as to what aspects of policy evaluation are examined. As with figure 1, figure 2 is developed from the separate 'Systematic Review' reference list provided at the end of the paper, which is discussed in section four. The figure is broken down into: calculating the energy consumption baseline, making gross savings adjustments, attributing energy savings, and monitoring and verification. 


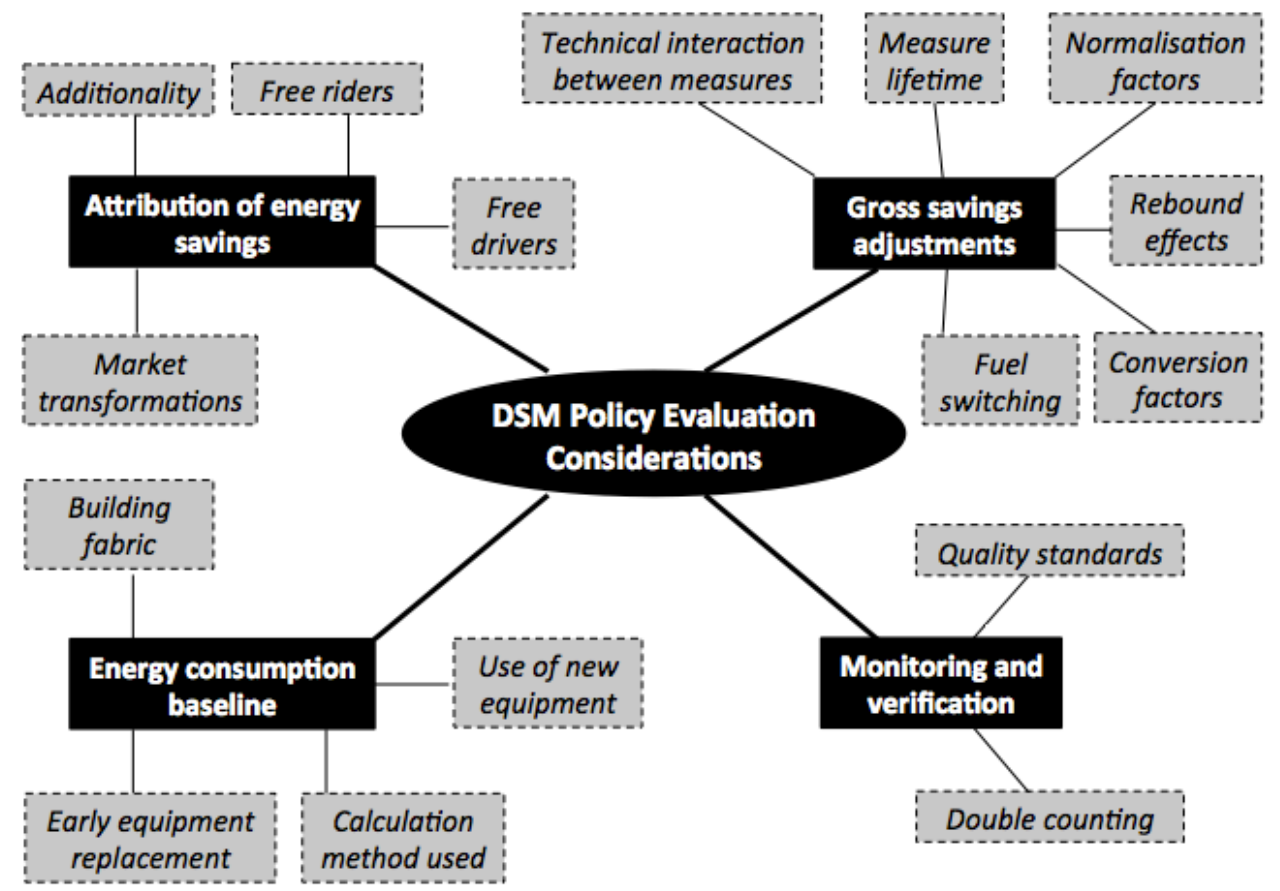

Figure 2: important considerations in demand-side policy evaluation

The energy consumption baseline refers to how the consumption that would have occurred without the programme (the baseline) was calculated. Making gross savings adjustments looks at how adjustments to energy savings were made, such as the lifetime of the measures installed or the degree of rebound effects, where financial savings from reduced energy consumption can be used to increase energy use overall, either directly (through the same activities) or indirectly (through other energy-consuming activities) (Sorrell, 2007; Sorrell et al., 2009). The attribution of energy savings refers to, for example, whether or not the programmes resulted in additional savings to what would have occurred had they not been implemented (additionality), or the degree of free ridership, where consumers would have still engaged with DSM in the absence of 
the programmes. Monitoring and verification looks at the degree of monitoring to assess the actual impacts of the programmes and to ensure that energy savings are not double counted.

A key part of the research was to fill an important gap on the quality of the evidence base for DSM policy evaluation. In order to do this, the research applied systematic review techniques to assess evidence quality, as outlined in the next section. Furthermore, a comprehensive metaevaluation of the global patterns of DSM policy implementation and evaluation is lacking in the literature. As discussed in section one, much of the previous research on DSM has focused on (non-government-stimulated) energy utility programmes, technological trials and modelling studies of the future potential of specific categories of DSM, such as demand response, energy efficiency or on-site generation/storage, rather than DSM policy implementation and evaluation.

\section{Methodology}

To explore the global evidence base, the research employed a systematic review to extract the vast majority of the relevant, high-quality ex-post evaluations that have been conducted on demand-side policies. The spatial and temporal breadth of the systematic review were not predefined, only the data sources that would be used for the search. A literature review was first conducted to identify the main databases and websites that publish evaluations of DSM policy.

The research undertook a pragmatic, inductive approach to science and utilised a mixedmethods type of systematic review based on the principles of realist synthesis (see Pawson and Tilley, 1997 and Pawson, 2002 for an overview of realist synthesis). Systematic reviews involve collating and synthesising all of the work that has been done on a particular intervention, trial or 
programme to better understand what works and what does not work (Petticrew and Roberts, 2006). Systematic reviews are a type of evidence review that is commonly confused with literature reviews. Evidence reviews are methods that aim to collect data and evidence for analysis using systematic techniques (such as detailed search strategies, inclusion criteria and quality assessments). In contrast, literature reviews aim to collate relevant studies on a particular topic using non-systematic techniques and appraise them in order to draw conclusions (Warren, 2015). A central aspect of this process is the identification of the key arguments and research gaps, and thus the purpose of literature reviews is not to collect data for analysis (Warren, 2015). Detailed comparisons of evidence reviews, literature reviews and different types of evidence reviews are provided in Warren (2017).

Systematic reviews have had limited attention in the energy and climate policy field in contrast to other disciplines, such as the medical sciences and some social science disciplines (e.g. education and social welfare), where they are an established method. Systematic reviews involve eight main stages as shown below:

\section{Review questions}

2. Selection of systematic review type

3. Search strategy

4. Inclusion/exclusion criteria

5. Quality assessment

6. Data/information extraction

7. Synthesis of findings

8. Dissemination of findings 
For the search strategy in stage three, a number of search terms were pilot tested to identify those that comprehensively returned the most relevant hits. In systematic reviews, a trade-off is usually made between the number of databases and sources included and the number of search terms used under resource and time constraints. The pilot tests identified that the breadth of sources was more important than an increased number of search terms in the context of the research question. One of the primary reasons for this is due to the sporadic distribution of the limited evidence base on ex-post DSM policy evaluation. A detailed discussion and justification of the search terms is provided in Warren (2015).

In stage four, it is crucial to identify what is considered relevant for answering the review question(s) determined in stage one. It also allows the review boundaries to be established based on the ability to access sources, the size of the review team, the time available to conduct the review and the budget dedicated to data collection. As such, the most commonly adopted sampling strategy for evidence reviews in the social sciences is purposive, nonprobability sampling. This research employed the inclusion criteria shown in table 1 :

\begin{tabular}{|l|}
\hline Inclusion Criteria \\
\hline Documents that answer the research questions \\
\hline Documents that discuss government-stimulated policies and programmes \\
\hline Documents that are written in English \\
\hline Documents that are ex-post policy evaluations \\
\hline Documents that are freely accessible and downloadable from the internet \\
\hline
\end{tabular}


Exclusion Criteria

Documents that look at DSM policy but not policy mechanisms and impacts

Documents that discuss utility-stimulated DSM programmes

Documents that discuss trials, pilots and small-scale R\&D programmes

Documents that model the future potential of DSM

Documents that discuss theoretical aspects of DSM policy

Documents that are not written in English

Documents from hand searching

Documents from referrals

Documents from bibliographies and 'snow-balling'

Table 1: the systematic review inclusion and exclusion criteria

Stage five is the most important stage in the systematic review process, as it entails the assessment of the quality of the documents that are deemed relevant after the search has been conducted. There are numerous study quality assessment scales used in the medical sciences, where systematic reviews have had the most attention, but many are based on quality criteria that are less relevant for energy policy evaluations. For example, the Jadad Scale (1998) scores documents based on whether or not the studies were randomised, blinded and withdrawal rates were stated. In energy policy evaluations, studies rarely involve standardised randomised control trials or equivalent and are often undertaken in different ways using different methods (Warren, 2014b). 
Systematic reviews have now become established in some social science disciplines, such as education and social welfare, as developed by the Campbell Collaboration and University-based research centres, such as the Evidence for Policy and Practice Information and Co-ordinating Centre (EPPI-Centre) at University College London (UCL). However, the method has had limited attention in the energy policy field, though some collaborations, such as the UK Energy Research Centre (UKERC)'s Technology and Policy Assessment (TPA) theme and the Collaboration for Environmental Evidence (CEE), are trying to fill this gap.

In the social sciences that use systematic reviews, there are number of study quality assessment scales that have been developed and tailored to answer specific research questions. For example, the TAPUPAS framework, as developed by Pawson et al. (2003), was developed primarily to address research questions in social care. The framework focuses on transparency (are the reasons for the study clear?), accuracy (is the study honestly based on relevant evidence?), Purposivity (is the method used suitable for the aims of the study?), utility (does the study provide answers to the questions it set?), propriety (is the study legal and ethical?), accessibility (can you understand the study?), and specificity (does the study meet the quality standards already used for this type of knowledge?).

However, the TAPUPAS framework has arguably wider applications than social care, as the quality criteria are broad enough to be relevant to other social science disciplines. Despite this, this research developed a new, more tailored scale that can be used to evaluate the quality of evidence in policy evaluations. By tailoring the scale to policy evaluation, a deeper understanding of the quality of the evidence base for ex-post demand-side policy evaluations 
could be obtained. The Warren scale was discussed and justified in Warren (2014b), but the scale is shown in full in figure 3.

4 points: Has the process for policy implementation been clearly explained?

- 1 point: Have details on the policy implementer been given?

- 1 point: Have details on how the policy was designed been given?

- 1 point: Have details on how the policy was implemented been given?

- 1 point: Have details on why the policy was implemented been given?

4 points: Has the process for policy evaluation been clearly explained?

- 1 point: Have details on the policy evaluator been given?

- 1 point: Have details on how the policy was evaluated been given?

- 1 point: Have details on the policy impacts been given?

- 1 point: Have details on policy success been given?

2 points: Has the document been peer reviewed or independently verified?

- 1 point: Has the document been peer reviewed by a reputable expert?

- 1 point: Has the document been peer reviewed by two or more reputable experts?

2 points: Are there statements of copyright, regulatory compliance, and possible conflicts of interest present?

- 1 point: Does the document give statements of copyright, regulatory compliance or possible conflicts of interest?

- 1 point: Does the document acknowledge resource contributions from people or institutions?

$>1$ point: Does the author/publishing organisation have a track record in the area?

1 point: Where percentages are given, are the totals given?

Figure 3: the Warren scale for assessing quality in energy policy evaluations

Documents must score at least half of the available points (i.e. $7 / 14$ points) to be included in the final sample. It is common in the systematic review literature to have scales with thresholds of half or two-thirds of the total number of points. An additional criteria is that at least one point must come from either of the two most heavily weighted parts of the scale (the processes for implementation and evaluation) and at least one point must come from another part of the scale. 
Once the final sample of high-quality documents has been established, stage six involves the extraction of relevant data and information from the documents. A summary of the quantitative metrics that were extracted in order to answer the research question is shown below:

- Evidence quality:

- Overall document sample size in each of the systematic review filtering stages in the production of the final sample

- Document samples sizes per data source in each of the filtering stages

- Spatial patterns:

- Number and location of countries / (sub-national) states in the final sample

- Number of documents and evaluations per country/state

- Temporal:

- Number of documents and evaluations per country/state per decade

- Policy patterns:

- Number of documents and evaluations per DSM policy

- Frequency of different policy objectives for implementing DSM policies

- Number and type of policy packages in the final sample

These metrics form the basis of the discussions in the next section. All extracted data were stored in a standardised spreadsheet-based analytical database. The full review protocol outlined in this section was pilot tested with two other researchers using two search terms in two databases (discussed further in Warren, 2015). This ensured that the review protocol was robust and could be replicated. 
The next section presents and discusses the results from the systematic review. Discussions centre around four main areas of analysis in order to determine the global evidence base and implementation patterns for demand-side policy: the overall patterns of evidence (in terms of data sources, DSM policies and countries/states), policy packages, temporal patterns and DSM policy objectives.

\section{Results}

\subsection{Overall Patterns}

Four stages of document filtering were conducted: initial hits in the data sources, hits after title skimming, hits after abstract skimming and applying the inclusion/exclusion criteria, and the final sample after the study quality assessment was applied. The data sources that were consulted are listed in table 2. These sources were determined in the literature review that was conducted prior to the systematic review (as discussed in section four) as the databases and websites that are more prominent in publishing evaluations of DSM. The number of initial hits and the number of documents in the final sample are given for each data source.

\begin{tabular}{|l|l|l|}
\hline Database Name & Final Sample Initial Hits \\
\hline Energy Policy & 1 & 549 \\
\hline Energy & 5 & 194 \\
\hline Energy Efficiency & 8 & 44 \\
\hline Energy Economics & 1 & 35 \\
\hline The Electricity Journal & 8 & 308 \\
\hline
\end{tabular}




\begin{tabular}{|c|c|c|}
\hline The Energy Journal & 0 & 0 \\
\hline Electric Power Systems Research & 0 & 18 \\
\hline Energy and Buildings & 1 & 35 \\
\hline Resource and Energy Economics & 1 & 20 \\
\hline Open Grey & 0 & 1 \\
\hline Google (Literature Review) & 5 & 58 \\
\hline American Council for an Energy-Efficient Economy (ACEEE) & 12 & 199 \\
\hline European Council for an Energy-Efficient Economy (ECEEE) & 14 & 61 \\
\hline IEA's Demand-Side Management Programme & 4 & 159 \\
\hline Association for the Conservation of Energy (ACE) & 1 & 7 \\
\hline National Grid & 0 & 3 \\
\hline $\begin{array}{l}\text { International Energy Program Evaluation Conference } \\
\text { (IEPEC) }\end{array}$ & 21 & 102 \\
\hline $\begin{array}{l}\text { International Partnership for Energy Efficiency Cooperation } \\
\text { (IPEEC) }\end{array}$ & 0 & 0 \\
\hline British Association for Energy Economics (BIEE) & 1 & 2 \\
\hline International Association for Energy Economics (IAEE) & 1 & 120 \\
\hline US Department of Energy (DoE) & 0 & 46 \\
\hline US DoE Energy Citations Database & 8 & 332 \\
\hline US Federal Energy Regulatory Commission (FERC) & 0 & 34 \\
\hline US Energy Information Administration (EIA) & 0 & 83 \\
\hline UK Department of Energy and Climate Change (DECC) & 4 & 664 \\
\hline UK Office of Gas and Electricity Markets (Ofgem) & 0 & 3 \\
\hline
\end{tabular}




\begin{tabular}{|l|l|l|} 
UK National Audit Office (NAO) & 0 & 1 \\
\hline $\begin{array}{l}\text { UK Public Accounts Committee for the House of Commons } \\
\text { (PAC) }\end{array}$ & 0 & 7 \\
\hline $\begin{array}{l}\text { China National Development and Reform Commission } \\
\text { (NDRC) }\end{array}$ & 0 & 0 \\
\hline Australia Energy Regulator (AER) & 0 & 600 \\
\hline Australia Department of Industry & 0 & 7 \\
\hline California Public Utilities Commission (CPUC) & 1 & 401 \\
\hline European Commission Department of Energy & 1 & 150 \\
\hline Thomas Reuters Web of Science & 4 & 79 \\
\hline Across 34 databases & 102 & 4,322 \\
\hline
\end{tabular}

Table 2: the databases and sources included in the systematic review

What is clear is that the sources that appear to produce the most initial hits are not necessarily the same sources that produce the most number of high-quality ex-post DSM policy evaluations. The databases and websites that produce $\geq 200$ initial hits are: DECC, AER, Energy Policy, CPUC, DoE Energy Citations Database and The Electricity Journal. However, the sources that have the most number of documents in the final sample are: IEPEC, ECEEE, ACEEE, DoE Energy Citations Database, The Electricity Journal and Energy Efficiency. Thus, only two sources (DoE Energy Citations Database and The Electricity Journal) overlap between the groups. These six sources represent the databases with the highest overall evidence quality for ex-post DSM policy evaluations. 
The total final sample size was 102 high-quality documents, which covered 690 ex-post evaluations (from the initial total hits of 4,322 documents). The number of documents did not equal the number of evaluations due to some documents including evaluations of more than one policy and country/state. Sub-national states and provinces also appeared in the sample, as some state-level governments have implemented demand-side policies independent of national governments (such as in the USA, China, Australia and Canada). There is a large body of evidence at the sub-national state and provincial level in some countries (particularly in the USA), and excluding their experiences would limit not only the sample size but also the accuracy and comprehensiveness of the global synthesis.

The evidence base is dominated by industry (59/102 documents), followed by academia (29/102 documents) and then government (14/102 documents). An important finding here is that globally, few high-quality ex-post evaluations of DSM policies have been conducted by governments. As discussed in section two, a number of academic discussions on the policy process make inherent assumptions that post-policy evaluation is an active part of the policy process for governments. In practice, the picture is much more mixed with regards to DSM policy. For example, the DoE Energy Citations Database includes primarily documents written by industry and academia, and high-quality ex-post evaluations produced by the US Department of Energy (DoE) appear limited. However, relative to other countries, DoE and the former UK Department of Energy and Climate Change (DECC) (now the Department for Business, Energy and Industrial Strategy (BEIS)) have been the more prominent government departments in evaluating demand-side policies. 
In terms of DSM policy types, alternative utility business models (such as the experiences in the USA at a state-level with decoupling policies and performance targets) (122/690 evaluations), information campaigns (including energy auditing) (118/690 evaluations), loans and subsidies (including tax incentives) (100/690 evaluations), utility obligations (89/690 evaluations) and performance standards (for appliances, equipment and buildings) (81/690 evaluations) have been the most frequently implemented and evaluated policies. In contrast, voluntary programmes (12/690 evaluations) and infrastructure rollouts (primarily smart meter rollouts) (4/690 evaluations) had the least number of policy evaluations. Despite this, the evidence base for infrastructure rollouts is likely to increase post-2020 following the implementation of the European Union (EU)'s Smart Meter Rollout Directive (Directive 2009/72/EC), which mandates that all countries in the EU must reach at least an $80 \%$ rollout of smart meters to small energy consumers by 2020 .

The evidence base is greatest in the USA (25/102), the UK (22/102) and the US state of California (20/102). France (13/102), China (12/102), Denmark (10/102), Italy (10/102), the US state of New York (9/102) and Germany (8/102) also perform well by the frequency of highquality evaluations.

Overall, 30 countries and 36 sub-national states have implemented at least one DSM policy and produced at least one high-quality ex-post evaluation. At a state-level, US states dominate the sample with 103/690 evaluations, 18/690 evaluations cover Chinese provinces, 13/690 evaluations cover Australian states, 4/690 evaluations cover a Belgian region (Flanders), 3/690 evaluations cover Canadian provinces and 1/690 evaluations covers an Indian state (Orissa). 


\subsection{Policy Packages}

Of the 690 evaluations, only 45 discussed DSM policy packages. Two possible explanations for this finding are that governments have prioritised the implementation of individual DSM policies rather than policy packages, as they usually entail lower administrative costs, or that evaluators have experienced methodological difficulties in separating out the individual impacts of policies within policy packages. Despite this, the most common policy packages in the sample are listed below by frequency:

$>$ Information campaigns / Loans and subsidies (13/690 evaluations)

> Performance standards / Labelling (10/690 evaluations)

$>$ Incentive payment-based demand response / Price-based demand response (7/690 evaluations)

$>$ Alternative utility business models / Market transformations (6/690 evaluations)

> Performance standards / Information campaigns (3/690 evaluations)

> Performance standards / Labelling / Utility obligations / Loans and subsidies (2/690 evaluations)

$>$ Voluntary programmes / Loans and subsidies (2/690 evaluations)

> Information campaigns / Loans and subsidies / Market transformations (1/690 evaluations)

> Performance standards / Labelling / Information campaigns (1/690 evaluations)

The information campaigns with loans and subsidies policy package is popular due to the complementary nature of the policies. If a government offers loans or grants to consumers for 
DSM measures (such as insulation or on-site generation), the policy is more likely to be successful if the incentives are marketed clearly. Countries/states that have implemented and evaluated this policy package include: China, Germany, Mexico, New Zealand, Sri Lanka, the USA and the following US states: Illinois, Massachusetts, Maine, Ohio, New Hampshire and Wisconsin.

The performance standards with labelling policy package is similarly popular due to the complementary nature of the policies. Introducing minimum energy efficiency standards for appliances, equipment or buildings have a greater chance of success in terms of manufacturing compliance and consumer education if they are clearly labelled (for example, with energy efficiency information, cost savings, carbon savings, etc.). The same argument applies to the performance standards with information campaigns policy package where manufacturing compliance and consumer education should improve if performance standards are marketed clearly. Countries/states that have implemented this policy package include: China, the EU, Pakistan, and the following Chinese provinces and regions: Shanghai, Beijing, Guangzhou, Hefei, Shandong, Sichuan and Jiangsu.

The demand response policy package has the third highest number of evaluations and this reflects the pattern that countries/states that have implemented demand response tend to introduce both incentive payment-based demand response and price-based demand response (PBDR) together, either individually or as a policy package. The former is concerned with providing direct payments or financial incentives to consumers to reduce demand during peak times, whereas the latter focuses on varying the price a consumer pays for energy at different times of the day or year (Albadi and El-Saadany, 2008). Much of the experience with demand 
response comes from the USA at a regional level through system operators, such as PJM, ISONE and NYISO. However, in recent years, China and some Chinese provinces have begun large-scale testing of demand response (notably Jiangsu, Beijing and Guangdong) (Wang et al., 2010).

The alternative utility business models with market transformations policy package is perhaps the most innovative of all of the policy packages included in the systematic review. It is a longer term policy that aims to change the underlying business models of energy utilities so that they can profit from demand-side options on an equal basis to supply-side options, whilst transforming the market for energy efficiency. The package is arguably the most challenging to implement, particularly from a political point of view, but it ensures that the regulatory restructuring of utility incentives is complemented with changes in the market by overcoming market barriers. There has been little experience with this policy package outside of the USA, reflecting the limited practical implementation of changing utility business models. Around half of US states have implemented specific types of alternative utility business models, such as decoupling policies or performance targets (NRDC, 2013), though the policy package has notably been implemented in the Pacific northwest region (which covers Oregon and Washington), California, New York and Massachusetts.

Policy packages that involve voluntary programmes with loans and subsidies tend to be introduced for longer term objectives, such as to help stimulate the market development of energy efficiency products and services. The UK, and to a lesser extent India, have experience with this combination of policies. Despite this, experience does not necessarily represent success. However, the focus of this paper is not to discuss policy impacts or the mechanisms 
for policy success and failure, which are the focus of the other main research question for this research.

Finally, where countries/states implement more than two policies within a policy package (such as performance standards with labelling, utility obligations and loans and subsidies, or information campaigns with loans and subsidies and market transformations, or performance standards with labelling and information campaigns), it often indicates a short-term response to an energy crisis (as occurred during the 2000-2001 electricity crisis in California), as shown in the four evaluations that covered such policy packages.

The main conclusion from this part of the analysis is that globally, there are nine categories of DSM policy packages that have been implemented and evaluated, with the information campaigns with loans and subsidies package forming the most frequent combination of policies, followed by the performance standards with labelling policy package and the demand response package. The information campaigns with loans and subsidies policy package has the greatest spatial diversity, covering countries in east-Asia, North America, Europe and Australasia; the performance standards with labelling policy package is dominated by experiences in Chinese provinces and European countries; and the demand response policy package has primarily been implemented at a regional level in the USA and to a lesser extent in China.

\subsection{Temporal Patterns}

In-depth analysis of temporal patterns was beyond the scope of the research project. However, with the data available, it is possible to give a broad overview of the frequency of evaluations in 
different decades since the energy crises of the 1970s. However, it is important to note that due to the limited digitisation of policy evaluations conducted prior to the 1990s, the paper does not seek to produce the same strength of conclusions as for the analysis of spatial patterns.

The results show that outside of the USA, the evidence base of high-quality ex-post DSM policy evaluations is limited in the 1970s and 1980s. However, in the USA there was much DSM policy activity in this period, reflecting the energy crises of 1973 and 1979, which led to the National Energy Conservation Policy Act and the Public Utility Regulatory Policy Act (PURPA), which were introduced as part of the National Energy Act 1978 (McNerney, 1998, p. 27).

In the 1990s, the global distribution of evaluations increased, particularly in Europe (notably Denmark, France, Germany, Italy, the Netherlands, Spain and Sweden) as the environmental agenda became more prominent, and east-Asia (notably China, India, Japan, South Korea and Thailand) as a result of energy security issues. The 2000 s appears to be the greatest period for the number of evaluations undertaken with $42 / 66$ countries/states showing more evaluations in this decade than in any other decade. In the 2010s, it is possible that the number of evaluations could overtake that of the 2000s if the analysis is extended post-2020, as only half of the decade could be included in the systematic review at the time of data collection. If the prediction turns out to be correct, the results would show that there has generally been an increase in the number of high-quality evaluations over time. However, due to the digitisation bias, further research is needed to validate this statement by including hand searching in the search strategy. 
At a state-level, the evidence base is dominated by US states across the decades. California has the greatest number of evaluations with a steady increase in frequency over time. Most of the evidence outside of California in the USA comes from the northeast (notably the New England and east coast states) and the northwest (notably the pacific north western states). For the northeast, a number of states begin evaluations in the 1990s and this increases in the 2000s. It is possible that the 2010 s could continue this trend, as previously stated. In contrast, for the northwest, a number of states begin evaluations earlier in the 1980s and the frequency decreases over time. It is important to reiterate that the results focus on the changing patterns of high-quality evaluations and not the actual implementation of DSM policies over time.

In China, a number of provinces begin evaluations in the 1990s (notably Jiangsu, Shanghai, Hebei and Fujian) and this increases in the 2000s. The other provinces and regions included in the research begin evaluations in the 2000s (notably Beijing, Guangzhou, Hefei, Shandong and Sichuan), though it is too early to comment on whether or not the trend continues in the 2010 s. In Australia, all four of the states included in the systematic review (New South Wales, the Australian Capital Territory, South Australia and Victoria) begin evaluations in the 2000s and this continues in the 2010s. In Canada, the two provinces included in the sample only show evaluations in the 1980s (British Columbia) and 1990s (Ontario). In Europe, the only subnational state to be included in the research is the Flanders region in Belgium, which begins evaluations in the 2000s though it is too early to comment on whether or not the trend continues in the 2010s. It is important to note that countries/states were determined inductively from the sample of documents and not pre-determined. 
The main conclusion from this part of the analysis is that globally, the number of high-quality evaluations appears to be increasing over time, particularly in recent decades (2000s and 2010s). This is especially the case in North America, Europe and east-Asia. More detailed temporal analysis is needed to explore this further and to validate the findings.

\subsection{Policy Objectives}

DSM policies are implemented for a variety of reasons, such as to ensure energy security, to enhance economic productivity (through energy efficiency and new business opportunities), to reduce carbon emissions and to reduce consumer energy bills. The systematic review extracted the primary policy objectives from each policy evaluation (as stated by the evaluators) and examined their frequency of discussion across DSM policies and countries/states in the sample. Figure 4 presents the overall results. 


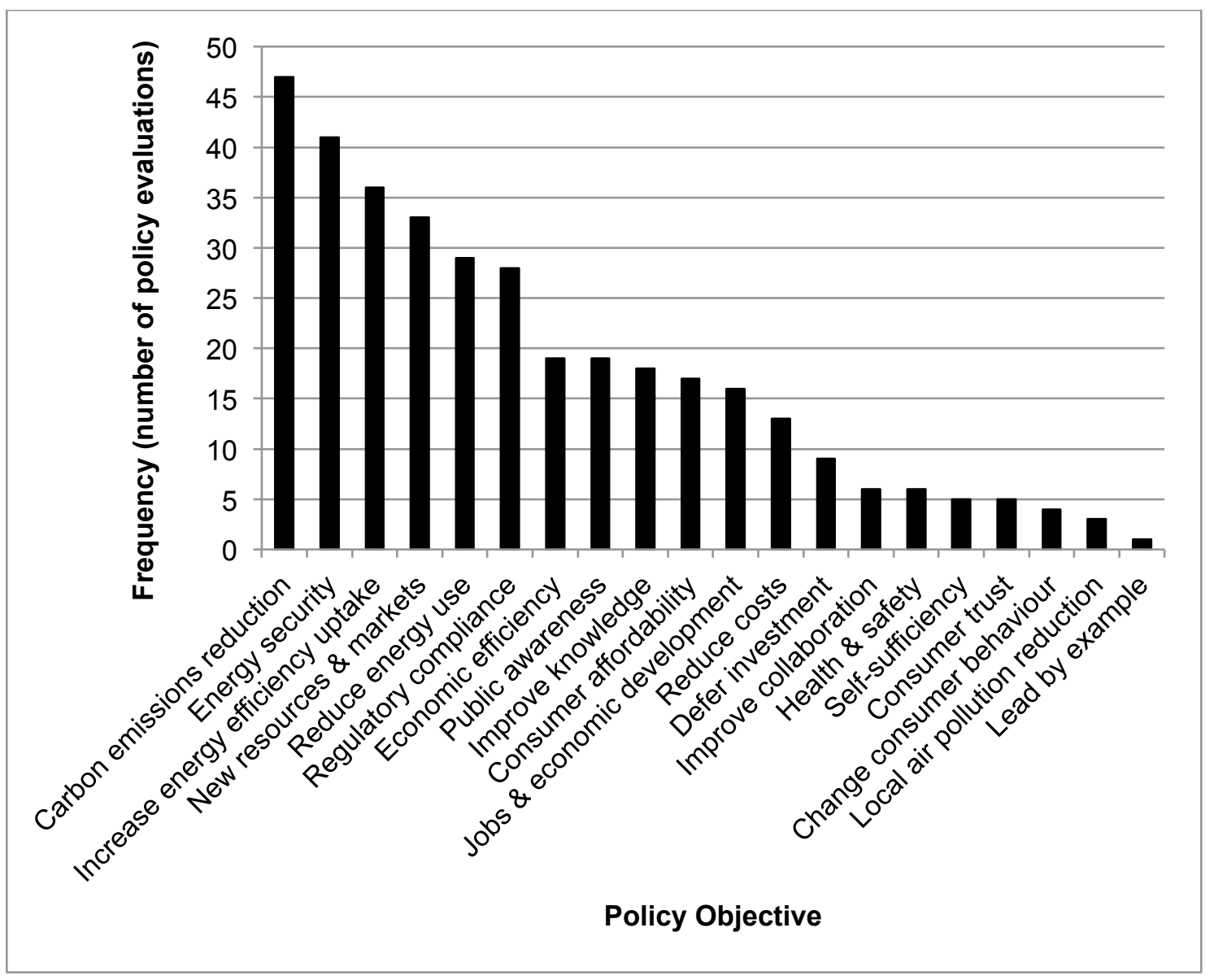

Figure 4: the primary objectives for DSM policy implementation

Where there were a number of evaluations within each document, policy objectives for each policy or country/state were noted (where stated by the evaluators). Overall, the top four reasons for countries/states to implement DSM policies are: to reduce carbon emissions (47 evaluations), to ensure energy security (41 evaluations), to increase the uptake of energy efficient technologies (36 evaluations) and to create new resources and markets (33 evaluations). 
The first policy objective refers to all aspects of environmental improvement except for local air pollution reduction. However, all 47 evaluations referred to the reduction in carbon emissions in some form. The second policy objective refers to the balance of supply and demand primarily at a national or state-level, though in one evaluation, it also referred to improving on-site energy security in buildings. Peak load reduction was commonly mentioned in the 41 evaluations and is considered part of the 'energy security' policy objective rather than the 'reduce energy use' policy objective. This is due to the latter referring to an overall reduction in energy use rather than load shifting. The third policy objective refers to a range of specific goals, such as to increase the uptake of certain technologies by consumers, to improve the national/state building fabric and value through retrofitting, and to improve the efficient use of energy across the country/state. The fourth policy objective refers to the creation of new markets for DSM, to introduce the demand-side as a resource on an equal basis to supply-side options and to stimulate investment in DSM.

Although carbon emissions reduction and energy security appear to be the main policy objectives for DSM in most countries/states, there is some spatial diversity between continents. In North America, enhanced productivity through energy efficiency and new markets has been a strong driver in recent decades. For example, the American Recovery and Reinvestment Act (ARRA) of 2009 devoted significant financial support to DSM, which led to rapid job creation and retention as well as a reduction in energy use and greenhouse gas emissions (Doris et al., 2009). 
In Europe, carbon emissions reduction and reducing consumer energy bills have become crucial drivers for DSM. For example, a number of the utility obligations in Europe (such as in the UK, Italy, France and Denmark) are aimed at reducing carbon emissions by meeting energy savings targets and have sub-targets for low-income groups to contribute to reducing fuel poverty (Giraudet et al., 2012; Bundgaard et al., 2013a; Eyre et al., 2009). Fuel poverty refers to consumers living on a low income in a home that cannot be kept warm at a reasonable cost, as defined in the UK's Warm Homes and Energy Conservation Act 2000 and reviewed in the Hills Fuel Poverty Review (2012). In Asia, particularly China, reducing local air pollution and preventing black-outs during crises have greatly expanded the development of DSM in recent years. The systematic review shows that much of the rapid growth in DSM has come from China (for example, see Bin and Jun, 2012; Pengcheng et al., 2012; and Zheng et al., 2012). The three documents that mentioned reducing local air pollution as a key policy objective were based on China. Preventing black-outs falls into the 'energy security' policy objective in figure 4 and was mentioned in the majority of the evaluations that focussed on China, as DSM is viewed as an important contributor to meeting the rapid growth in energy demand in the country.

\section{Conclusion}

The paper presented some of the results of a four-year project to systematically review the global evidence base for demand-side management (DSM) policy. A comprehensive metaevaluation of the evidence base across the full range of DSM policy types is lacking in the literature and the paper aimed to contribute to filling this gap by answering the following research question: What DSM policies have been implemented around the world with highquality documented evaluations? The research employed a systematic review of the evidence 
base and identified 102 high-quality documents covering 690 ex-post policy evaluations from 34 databases and sources (from an initial sample of 4,322 documents). The documents covered 30 countries and 36 sub-national states across six continents, and twelve individual types of DSM policy and nine DSM policy packages. Spatially, the USA, the UK, California, France and China have the greatest number of high-quality documents in the final sample.

The findings show that the top-five most frequently implemented and evaluated DSM policies are alternative utility business models (such as decoupling policies and performance targets), information campaigns, loans and subsidies, utility obligations, and performance standards. The primary policy objective for DSM is to reduce carbon emissions, followed by ensuring energy security, increasing the uptake of energy efficient technologies, and creating new resources and markets. It is clear that individual DSM policies are more commonly implemented and evaluated than DSM policy packages, as just 45/690 evaluations focussed on policy packages. Of these, information campaigns in combination with loans and subsidies, and performance standards in combination with labelling, are the more commonly implemented and evaluated policy packages. Although temporal patterns were not the central focus of the analysis due to the potential digitisation bias for evaluations, the results show that the number of high-quality expost evaluations have increased over time since the energy crises of the 1970s. Overall, this paper argues that demand-side policy will play an increasingly important role as a complement to low carbon activities on the supply-side in the transition to a more environmentally sustainable energy system.

With greater time and resources, the systematic review could be extended to include nonEnglish documents (translators would be required), hand searching for non-electronic 
documents (access to specified libraries and organisations would be required), snowballing and referrals. In particular, this would allow more detailed temporal analysis to be conducted. Furthermore, future research with greater resources should utilise the same methodological approach and examine the specific policy level (for example, energy audits rather than information campaigns), either within a specific category of DSM (energy efficiency, demand response or on-site generation/storage) or across the range of categories.

From the analysis, it is clear that the evidence base for high-quality ex-post demand-side policy evaluations is limited with most evaluations being produced by industry rather than governments or academia. Thus, there is a need to encourage evaluation practices in governments to ensure that enough resources are dedicated to post-policy evaluation in order to improve the design and implementation of future DSM policies. Such an approach should aim to establish institutional learning beyond lessons learned to use robust ex-post evaluation methods to inform future ex-ante appraisals and pre-policy impact assessments. Despite this, the potential political bias of governments not wanting to publicly evaluate and declare policies that did not perform as well as originally anticipated remains an important challenge that warrants further attention. Overall, the evaluation practices published in sources such as the International Energy Program Evaluation Conference (IEPEC), the European Council for an Energy-Efficient Economy (ECEEE), the American Council for an Energy-Efficient Economy (ACEEE), the US Department of Energy (DoE)'s Energy Citations Database, The Electricity Journal and Energy Efficiency are good role models for the production of high-quality DSM evaluations.

Acknowledgements 
This research was made possible by UK EPSRC support, grant number EP/H009612/1. I would like to thank the anonymous peer reviewers for their comments on the paper.

Bibliography:

1. Albadi and El-Saadany (2008) "A summary of demand response in electricity markets", Electric Power Systems Research, 78, pp. 1989-1996

2. Behavioural Insights Team (2011) Annual Update 2010-2011 Report, Cabinet Office, London, UK

3. Bin, S. and Jun, L. (2012) "Building Energy Efficiency Policies in China", American Council for an Energy-Efficient Economy (ACEEE), Research Report E129, June 2012

4. Bundgaard, S.S., Dyhr-Mikkelsen, K., Larsen, A.E. and Togeby, M. (2013a) "Energy Efficiency Obligation Schemes in the EU - Lessons Learned from Denmark", First quarter 2013, International Association for Energy Economics (IAEE)

5. Campbell Collaboration website: http://www.campbellcollaboration.org

6. Collaboration for Environmental Evidence (CEE) website: http://www.environmentalevidence.org

7. Dawnay and Shah (2011) "Behavioural economics: seven key principles for environmental policy”, Chapter 4 (pp. 74-99), in: Dietz, S., Mitchie, J. and Oughton, C. (2011) The Political Economy of the Environment: An Interdisciplinary Approach, Routledge, UK

8. Doris, E., Cochran, J. and Vorum, M. (2009) "Energy Efficiency Policy in the United States: Overview of Trends at Different Levels of Government", report number NREL/TP-6A246532, National Renewable Energy Laboratory, Department of Energy (DoE), USA

9. European Council Directive 2009/72/EC on smart meter rollout 
10. Evidence for Policy and Practice Information and Co-ordinating Centre (EPPI-Centre): http://eppi.ioe.ac.uk/cms/

11. Eyre, N., Pavan, M. and Bodineau, L. (2009) "Energy company obligations to save energy in Italy, the UK and France: what have we learnt?", ECEEE Summer Study 2013 Proceedings, European Council for an Energy-Efficient Economy (ECEEE)

12. Fischer, F. (1995) Evaluating public policy, Chicago: Nelson-Hall Publishers

13. Gellings, C.W. and Chamberlin, J.H. (1993) Demand-Side Management: Concepts and Methods, $2^{\text {nd }}$ Edition, The Fairmont Press, Inc., USA

14. Giraudet, L.-G., Bodineau, L. and Finon, D. (2012) "The costs and benefits of white certificates schemes", Energy Efficiency, 5, pp. 179-199

15. Grubb, M. (2014) "Tried and tested - four decades of energy efficiency policy", chapter five in: Grubb (2014) Planetary Economics: Energy, climate change and the three domains of sustainable development, Routledge, UK

16. Hill, M. (2009) The Public Policy Process, $5^{\text {th }}$ Edition, Harlow: Pearson Education Limited, p. 143

17. Hills, J. (2012) "Getting the measure of fuel poverty - final report of the Fuel Poverty Review", CASE report 72, Centre for Analysis of Social Exclusion (CASE), March 2012

18. Hogwood, B.W. and Gunn, L.A. (1984) Policy Analysis for the Real World, Oxford University Press

19. Jadad, A. (1998) Randomised controlled trials: a users guide, London: BMJ Books, UK

20. John, P. (1998) Analysing Public Policy, Creative Print and Design (Wales), UK, pp. 196

21. John, P. (2011) Making Policy Work, Routledge, UK, pp. 10

22. McNerney, R.A. (1998) Changing Structure of the Electric Power Industry: An Update, Chapter 4, pp. 27-28, DIANE Publishing 
23. Mundaca, T.L. and Neij, L. (2010) "A meta-analysis of bottom-up ex-ante energy policy evaluation studies", In proceedings of the 2010 International Energy Program Evaluation Conference, 'Counting on Energy Programs - It's Why Evaluation Matters', Paris, France, International Energy Program Evaluation, 2010

24. Nagel, S.S. (2002) Handbook of Public Policy Evaluation, Sage Publications, USA

25. National Energy Act 1978, Washington DC: National Congress, USA

26. National Energy Conservation Policy Act of 1978, Washington DC: National Congress, USA

27. Natural Resources Defense Council (NRDC) (2013) "Decoupling Across the United States", Map, August 2013, can be downloaded from: http://www.nrdc.org/energy/decoupling [accessed on 13/01/14]

28. Pawson, R. (2002) “Evidence-based policy: the promise of 'Realist Synthesis'”, Evaluation, 8 (3), pp. $340-35$

29. Pawson, R. and Tilley, N. (1997) Realistic Evaluation, London: SAGE

30. Pawson, R., Boaz, A., Grayson, L., Long, A. and Barnes, C. (2003) "SCIE Knowledge review 03: Types and quality of knowledge in social care", Social Care Institute for Excellence (SCIE), November 2003

31. Pengcheng, L., Meng, L., Haihong, C. and Yan, L. (2012) "China's practices on evaluating the energy savings of mandatory energy efficiency standards", International Energy Program Evaluation Conference 2012

32. Petticrew, M. and Roberts, H. (2006) Systematic Reviews in the Social Sciences, Blackwell Publishing, Oxford, UK

33. Public Utility Regulatory Policy Act of 1978, Washington DC: National Congress, USA 
34. Sorrell, S. (2007) "The Rebound Effect: an assessment of the evidence for economy-wide energy savings from improved energy efficiency", report produced for the UK Energy Research Centre (UKERC), October 2007

35. Sorrell, S. (2015) "Reducing energy demand: a review of issues, challenges and approaches", Renewable and Sustainable Energy Reviews, 47, pp. 74-82

36. Sorrell, S., Dimitropoulos, J. and Sommerville, M. (2009) "Empirical estimates of the direct rebound effect: a review", Energy Policy, 37, pp. 1356-1371

37. Stern, F. and Vantzis, D. (2014) "Protocols for Evaluating Energy Efficiency - Both Sides of the Atlantic", International Energy Policy and Programme Evaluation Conference, 9-1 $11^{\text {th }}$ September 2014, Berlin, Germany

38. Strachan, N. and Warren, P. (2011) "Incorporating behavioural complexity in energyeconomic models", UK Energy Research Centre Conference on: Energy and People: Futures, Complexity and Challenges, 20-21 September 2011, Environmental Change Institute, Oxford, UK

39. Thaler, R.H. and Sunstein, C.R. (2008) Nudge: Improving Decisions About Health, Wealth, and Happiness, Yale University Press

40. UK Energy Research Centre (UKERC)'s Technology and Policy Assessment (TPA) theme website: http://www.ukerc.ac.uk/programmes/technology-and-policy-assessment.html

41. Wang, J., Bloyd, C.N., Hu, Z. and Tan, Z. (2010) "Demand response in China", Energy, 35 (4), pp. 1592-1597

42. Warm Homes and Energy Conservation Act of 2000, London: HMSO, UK

43. Warren, P. (2014a) "A review of demand-side management policy in the UK", Renewable and Sustainable Energy Reviews, 29, pp. 941-951 
44. Warren, P. (2014b) "The use of systematic reviews to analyse demand-side management policy", Energy Efficiency, 7, pp. 417-427

45. Warren, P. (2015) Demand-Side Management Policy: Mechanisms for Success and Failure, PhD thesis, University College London (UCL), UK

46. Warren, P. (2017) "The use of evidence reviews to inform demand-side policy", ECEEE Summer Study 2017, European Council for an Energy-Efficiency Economy (ECEEE), 29 ${ }^{\text {th }}$ May $-3^{\text {rd }}$ June 2017, Presqu'île de Giens, France

47. Zheng, N., Zhou, N., Fino-Chen, C. and Fridley, D. (2012) "Evaluation of local enforcement of energy efficiency standards and labeling program in China", International Energy Program Evaluation Conference 2012

Systematic Review:

1. Agnew, K., Burke, R. and Ham-su, P. (2009) "Participation of demand response resources in ISO New England's Ancillary Service Markets", International Energy Program Evaluation Conference 2009

2. Arsenault, E., Bernard, J.-T. and Genest-Laplante, E. (1996) "Hydro-Québec energy savings programs: 'Watt' are they worth?", Resource and Energy Economics, 18 (1), pp. 65-81

3. Association for the Conservation of Energy (ACE) (2013) Financing energy efficiency in buildings: an international review of best practice and innovation, A report to the World Energy Council, October 2013

4. Atanasiu, B. and Constantinescu, T. (2011) "A comparative analysis of the energy performance certificates schemes within the European Union: Implementing options and 
policy recommendations", ECEEE Summer Study 2013 Proceedings, European Council for an Energy-Efficient Economy (ECEEE)

5. Bachrach, D. (2003) "Energy Efficiency Leadership in California: Preventing the Next Crisis", The Electricity Journal, 16 (6), pp. 37-47

6. Bertoldi, P. and Rezessy, S. (2007) "Assessment of White Certificate Schemes and their energy saving evaluation methods", International Energy Program Evaluation Conference 2007

7. Bertoldi, P. and Rezessy, S. (2008) "Tradable white certificate schemes: fundamental concepts", Energy Efficiency, 1, pp. 237-255

8. Betz, R., Jones, M.C., MacGill, I. and Passey, R. (2013) "Trading in energy efficiency in Australia: What are the lessons learnt so far?', ECEEE Summer Study 2013 Proceedings, European Council for an Energy-Efficient Economy (ECEEE)

9. Bin, S. and Jun, L. (2012) "Building Energy Efficiency Policies in China", American Council for an Energy-Efficient Economy (ACEEE), Research Report E129, June 2012

10. Broc, J.-S., Melo, C.A. and Jannuzzi, G. (2012) "Detailed comparison of Brazilian and French obligation schemes to promote energy efficiency", International Energy Program Evaluation Conference 2012

11. Brown, M.A. and Mihlmester, P.E. (1995) "What has DSM achieved in California?", report number CONF-950643-1, Department of Energy (DoE), USA

12. Bukarica, V., Debrecin, N., Borkovic, Z.H. and Pesut, D. (2012) "Evaluating energy savings arising from NEEAP implementation: lessons learned in Croatia", International Energy Program Evaluation Conference 2012 
13. Bundgaard, S.S., Dyhr-Mikkelsen, K., Larsen, A.E. and Togeby, M. (2013) "Energy Efficiency Obligation Schemes in the EU - Lessons Learned from Denmark", First quarter 2013, International Association for Energy Economics (IAEE)

14. Bundgaard, S.S., Togeby, M., Dyhr-Mikkelsen, K., Sommer, T., Kajaerbye, V.H. and Larsen, A.E. (2013) "Spending to save: evaluation of the energy efficiency obligation in Denmark", ECEEE Summer Study 2013 Proceedings, European Council for an EnergyEfficient Economy (ECEEE)

15. Cappers, P., Goldman, C. and Kathan, D. (2010) "Demand response in U.S. electricity markets: Empirical evidence", Energy, 35 (4), pp. 1526-1535

16. Cappers, P., Goldman, C.A. and Kathan, D. (2009) "Demand Response in US Electricity Markets: Empirical Evidence", report number LBNL-2124E, Ernest Orlando Lawrence Berkeley National Laboratory, USA

17. Centre for Strategy \& Evaluation Services (2012) "Evaluation of the Ecodesign Directive", Final report, UK

18. Colby, J. and Davis, S. (2011) "Can short term ARRA stimulus funding achieve long term market transformation?", International Energy Program Evaluation Conference 2011

19. Crossley, D. (2008) "Tradeable energy efficiency certificates in Australia", Energy Efficiency, 1, pp. 267-281

20. Crossley, D. (2010) "International best practice in using energy efficiency and demand management to support electricity networks", Report 4 - Scaling the Peaks: Demand Management and Electricity Networks, Australian Alliance to Save Energy, Australia

21. Di Santo, D., Forni, D., Venyurini, V. and Biele, E. (2011) "The white certificate scheme: the Italian experience and proposals for improvement", ECEEE Summer Study 2013 Proceedings, European Council for an Energy-Efficient Economy (ECEEE) 
22. Doris, E., Cochran, J. and Vorum, M. (2009) "Energy Efficiency Policy in the United States: Overview of Trends at Different Levels of Government", report number NREL/TP-6A246532, National Renewable Energy Laboratory, Department of Energy (DoE), USA

23. Drew, T. (2009) "An assessment of California's energy efficiency incentive mechanism", International Energy Program Evaluation Conference 2009

24. Eyre, N. (2008) "Regulation of energy suppliers to save energy - lessons from the UK debate", British Institute of Energy Economists (BIEE)

25. Eyre, N., Pavan, M. and Bodineau, L. (2009) "Energy company obligations to save energy in Italy, the UK and France: what have we learnt?", ECEEE Summer Study 2013 Proceedings, European Council for an Energy-Efficient Economy (ECEEE)

26. Fleiter, T., Gruber, E., Eichhammer, W. and Worrell, E. (2012) "The German energy audit program for firms - a cost-effective way to improve energy efficiency?", Energy Efficiency, 5, pp. 447-469

27. Friedmann, R. and Sheinbaum, C. (1998) "Mexican electric end-use efficiency: experiences to date", Annual Review of Energy and the Environment, 23, pp. 225-252

28. Gillich, A. and Sunikka-Blank, M. (2013) "Barriers to domestic energy efficiency - an evaluation of retrofit policies and market transformation strategies", ECEEE Summer Study 2013 Proceedings, European Council for an Energy-Efficient Economy (ECEEE)

29. Gillingham, K., Newell, R. and Palmer, K. (2006) "Energy efficiency policies: a retrospective examination", Annual Review of Environment and Resources, 31, pp. 161-192

30. Giraudet, L.-G., Bodineau, L. and Finon, D. (2012) "The costs and benefits of white certificates schemes", Energy Efficiency, 5, pp. 179-199 
31. Gold, R. and Nadel, S. (2011) "Assessing the Harvest: Implementation of the Energy Efficiency Provisions in the Energy Policy Act of 2005", American Council for an EnergyEfficient Economy (ACEEE), Research Report E113, March 2011

32. Gold, R. and Nadel, S. (2011) "Energy Efficiency Tax Incentives, 2005-2011: How Have They Performed?", American Council for an Energy-Efficient Economy (ACEEE), White Paper on Tax Incentives, June 2011

33. Gold, R., Nadel, S., Laitner, J.A. and deLaski, A. (2011) "Appliance and Equipment Efficiency Standards: A Moneymaker and Job Creator", American Council for an EnergyEfficient Economy (ACEEE), Research Report A111, January 2011

34. Goldman, C.A. and Kito, M.S. (1994) "Review of Demand-Side Bidding Programs: Impacts, Costs and Cost-Effectiveness", report number LBL-35021, Lawrence Berkeley National Laboratory and the University of California, USA

35. Goldman, C.A., Stuart, E., Hoffman, I., Fuller, M.C. and Billingsley, M.A. (2011) "Interactions between Energy Efficiency Programs funded under the Recovery Act and Utility Customer-Funded Energy Efficiency Programs", report number LBNL-4322E, Ernest Orlando Lawrence Berkeley National Laboratory, USA

36. Gruber, E., Fleiter, T., Mai, M. and Frahm, B.-J. (2011) "Efficiency of an energy audit programme for SMEs in Germany - results of an evaluation study", ECEEE Summer Study 2013 Proceedings, European Council for an Energy-Efficient Economy (ECEEE)

37. Guertler, P., Royston, S. and Robson, D. (2013) "Somewhere between a 'Comedy of errors' and 'As you like it'? A brief history of Britain's 'Green Deal' so far", ECEEE Summer Study 2013 Proceedings, European Council for an Energy-Efficient Economy (ECEEE)

38. Hadley, S. and Hirst, E. (1995) "Utility DSM programs from 1989 through 1998: continuation or cross roads?", report number ORNL/CON-405, Oak Ridge National Laboratory, USA 
39. Harmelink, M., Nilsson, L. and Harmsen, R. (2008) "Theory-based policy evaluation of 20 energy efficiency instruments", Energy Efficiency, 1, pp. 131-148

40. Heffner, G.C., Lees, E., Crossley, D. and Migden-Ostrander, J. (2012) "Evaluating policies for energy provider-delivered energy efficiency", International Energy Program Evaluation Conference 2012

41. Hong, T. (2009) "A close look at the China Design Standard for Energy Efficiency of Public Buildings", Energy and Buildings, 41, pp. 426-435

42. Horowitz (2013) "Purchased energy and policy impacts in the US manufacturing sector", Energy Efficiency, April 2013

43. IEA DSM Programme (2004) "INDEEP Analysis Report 2004", Task 1 Subtask 8 International Database on Demand-Side Management Technologies and Programmes, International Energy Agency (IEA)

44. IEA DSM Programme (2005) "Evaluation Guidebook Volume 2 - Country Reports and Case Examples Used for the Evaluation Guidebook", Task 1 Subtask 9 - Evaluation Guidebook on the impact of DSM and Energy Efficiency Programmes for Kyoto's GHG Targets, International Energy Agency (IEA)

45. IEA DSM Programme (2006) "Task 14 Final Report", Task 14 - Market Mechanisms for White Certificate Trading, International Energy Agency (IEA)

46. IEA DSM Programme (2008) "Evaluation and Acquisition of Network-driven DSM Resources", Task 15 - Network driven DSM, International Energy Agency (IEA)

47. International Institute for Energy Conservation (IIEC) Demand Side Management: Best Practices Guidebook for Pacific Island Power Utilities, Report prepared for the South Pacific Applied Geoscience Commission (SOPAC) and the United Nations Department of Economic and Social Affairs (UNDESA) 
48. Kimura, O. (2009) "Is public R\&D in energy efficiency really effective? - a case in Japan and its implications", ECEEE Summer Study 2013 Proceedings, European Council for an Energy-Efficient Economy (ECEEE)

49. Kushler, M. and Vine, E. (2003) "Examining California's Energy Efficiency Policy Response to the 2000/2001 Electricity Crisis: Practical Lessons Learned Regarding Policies, Administration, and Implementation", American Council for an Energy-Efficient Economy (ACEEE), Research Report U033, March 2003

50. Kushler, M., Nowak, S. and Witte, P. (2012) "A National Survey of State Policies and Practices for the Evaluation of Ratepayer-Funded Energy Efficiency Programs", American Council for an Energy-Efficient Economy (ACEEE), Research Report U122, February 2012

51. Kushler, M., York, D. and Witte, P. (2004) "Five Years In: An Examination of the First HalfDecade of Public Benefits Energy Efficiency Policies", American Council for an EnergyEfficient Economy (ACEEE), Research Report U041, April 2004

52. Lee, A.D., Onisko, S.A., Sandahl, L.J. and Butler, J. (1994) "Everyone wins! — A program to upgrade energy efficiency in manufactured housing", The Electricity Journal, 7 (2), pp. $77-87$

53. Lees, E. (2006) "Evaluation of the Energy Efficiency Commitment 2002-2005", Report to DEFRA, prepared by Eoin Lees Energy, 28th February 2006, UK

54. Lees, E. (2008) "Evaluation of the Energy Efficiency Commitment 2005-2008", Report to DEFRA, prepared by Eoin Lees Energy, 28th February 2006, UK

55. Lepetitgaland, K.K., Vasconcellos, L.E.M., Magalhaes, L.P., Costa, A.L.P., Costa, L.F.T. and Friedmann, R. (2011) "The strategic value of evaluation for Brazil and Neighbouring countries: the experience of Procel", International Energy Program Evaluation Conference 2011 
56. Lowry, M., Irwin, S. and Waeckerlin, E. (2004) "Demand Response in the West: Lessons for States and Provinces", report prepared for the Department of Energy (DoE), USA

57. Mallaburn, P.S. and Eyre, N. (2013) "Lessons from energy efficiency policy and programmes in the UK from 1973 to 2013", Energy Efficiency, February 2013

58. McRae, M., James, A., Kim, A. and Spahic, M. (2011) "Measuring diffusion in a market transformation program", International Energy Program Evaluation Conference 2011

59. Meyers, E.M. and Hu, G.M. (1999) "Demand-Side Carbon Reduction Strategies in an Era of Electric Industry Competition", The Electricity Journal, 12 (1), pp. 72-81

60. Murray, M. (2010) "Evaluation of the effectiveness and impact of energy efficiency advertising campaigns", International Energy Program Evaluation Conference 2010

61. Nadal, S., Amann, J., Hayes, S., Bin, S., Young, R., Mackres, E., Misuriello, H. and Watson, S. (2013) "An Introduction to US Policies to Improve Building Efficiency, American Council for an Energy-Efficient Economy (ACEEE), Research Report A134, July 2013

62. Nadel, S. and Gold, R. (2010) "Utility DSM: Off the Coasts and into the Heartland", The Electricity Journal, 23 (8), pp. 51-62

63. Nadel, S. and Kushler, M. (2000) "Public Benefit Funds: A Key Strategy for Advancing Energy Efficiency", The Electricity Journal, 13 (8), pp. 74-84

64. Neubauer, M., Foster, B., Elliott, N., White, D. and Hornby, R. (2013) "Ohio's Energy Efficient Resource Standard: Impacts on the Ohio Wholesale Electricity Market and Benefits to the State", American Council for an Energy-Efficient Economy (ACEEE), Research Report E138, April 2013

65. Neumann, R. (2013) "Trials and tribulations of joint electric and gas programs - guidelines in integrating joint DSM", International Energy Program Evaluation Conference 2013 
66. Nishio, K. and Ofuji, K. (2012) "Behavior change and driving forces to save electricity in the electricity crisis in Japan", International Energy Program Evaluation Conference 2012

67. O'Drain, M.J. and Edwards, C.M. (2010) "Evaluating low income energy efficiency programs: getting results in California", International Energy Program Evaluation Conference 2010

68. Pengcheng, L., Meng, L., Haihong, C. and Yan, L. (2012) "China's practices on evaluating the energy savings of mandatory energy efficiency standards", International Energy Program Evaluation Conference 2012

69. Prindle, W., Dietsch, N., Elliott, R.N., Kushler, M., Langer, T. and Nadel, S. (2003) "Energy Efficiency's Next Generation: Innovation at the State Level", American Council for an Energy-Efficient Economy (ACEEE), Research Report E031, November 2003

70. Regulatory Assistance Project (RAP) (2012) "Policies to achieve greater energy efficiency", Global Power Best Practice Series, October 2012

71. Rosenow, J. (2011) "Different paths of change: Home energy efficiency policy in Britain and Germany", ECEEE Summer Study 2013 Proceedings, European Council for an EnergyEfficient Economy (ECEEE)

72. Rosenow, J. and Galvin, R. (2013) "Evaluating the evaluations: evidence from energy efficiency programmes in Germany and the UK", Energy and Buildings, 62, pp. 450-458

73. Schultz, D. and Eto, J. (1990) "Carrots and sticks: Shared-savings incentive programs for energy efficiency", The Electricity Journal, 3 (10), pp. 32

74. Sciortino, M., Nowak, S., Witte, P., York, D. and Kushler, M. (2011) "Energy Efficiency Resource Standards: A Progress Report on State Experience", American Council for an Energy-Efficient Economy (ACEEE), Research Report U112, June 2011 
75. Smith, S. and Thorne, J. (2003) "An evaluation of the EnergyGuide Label: what we learned.", International Energy Program Evaluation Conference 2003

76. Southern California Edison (SCE) (2007) "2007 Energy Efficiency Annual Report", November 2007, USA

77. Spees, K. and Lave, L.B. (2007) "Demand Response and Electricity Market Efficiency", The Electricity Journal, 20 (3), pp. 69-85

78. Sumi, D. and Prahl, R. (2001) "A comprehensive examination of the market effects of a public benefits-sponsored pilot program: lessons learned from Wisconsin's Focus on Energy", International Energy Program Evaluation Conference 2001

79. Suna, D. and Haas, R. (2013) "How to calculate energy savings and costs of energy saving obligations in a harmonized way?", ECEEE Summer Study 2013 Proceedings, European Council for an Energy-Efficient Economy (ECEEE)

80. Taylor, B., Trombley, D. and Reinaud, J. (2012) "Energy Efficiency Resource Acquisition Program Models in North America", American Council for an Energy-Efficient Economy (ACEEE), Research Report IE126, November 2012

81. Tholen, L., Kiyar, D., Venjakob, M., Xia, C., Thomas, S. and Aydin, V. (2013) "What makes a good policy? Guidance for assessing and implementing energy efficiency policies", ECEEE Summer Study 2013 Proceedings, European Council for an Energy-Efficient Economy (ECEEE)

82. Titus, E., Michals, J., Hurley, D., Osann, E.R. and Waite, S. (2009) "Energy efficiency as a resource in the PJM Capacity Market", International Energy Program Evaluation Conference 2009 
83. Togeby, M., Dyhr-Mikkelsen, K., Larsen, A., Hansen, M.J. and Bach, P. (2009) "Danish energy efficiency policy: revisited and future improvements", ECEEE Summer Study 2013 Proceedings, European Council for an Energy-Efficient Economy (ECEEE)

84. UK Department of Energy and Climate Change (DECC) (2011) "Energy supplier obligation policies: evaluation synthesis", Research Report, October 2011, DECC

85. UK Department of Energy and Climate Change (DECC) (2011) "Evaluation of the Community Energy Saving Programme", Research Report, October 2011, DECC

86. UK Department of Energy and Climate Change (DECC) (2011) "Evaluation of the Low Carbon Buildings Programme", Research Report, August 2011, DECC

87. UK Department of Energy and Climate Change (DECC) (2011) "Low Carbon Building Programme 2006-2011", Final Report, August 2011, DECC

88. Vine, E., Rhee, C.H. and Lee, K.D. (2006) "Measurement and evaluation of energy efficiency programs: California and South Korea", Energy, 31 (6-7), pp. 1100-1113

89. Waide, P. and Buchner, B. (2008) "Utility energy efficiency schemes: savings obligations and trading", Energy Efficiency, 1 (4), pp. 297-311

90. Walawalkar, R., Fernands, S., Thakur, N. and Chevva, K.R. (2010) "Evolution and current status of demand response (DR) in electricity markets: Insights from PJM and NYISO", Energy, 35 (4), pp. 1553-1560

91. Wang, J., Bloyd, C.N., Hu, Z. and Tan, Z. (2010) "Demand response in China", Energy, 35 (4), pp. 1592-1597

92. Wikler, G.A. (2000) "Policy Options for Energy Efficiency Initiatives", The Electricity Journal, 13 (1), pp. 61-68 
93. Wirtshafter, R.M., Harper, B., Faesy, R., Reed, G., Badger, L., Chiodo, J., Killian, E. and George, K. (2011) "The costs and benefits of measuring if States meet 90\% compliance with Building Codes", International Energy Program Evaluation Conference 2011

94. Wirtshafter, R.M., Parlin, K., Hungerford, D., McKinley, K. and Bordner, R. (2007) "Desperately seeking savings from small scale demand response: the California experience", International Energy Program Evaluation Conference 2007

95. Yang, M. and Rumsey, P. (1997) "Energy conservation in typical Asian countries", Energy Sources, 19 (5), pp. 507-521

96. Yu, Y. (2010) "Policy redesign for solving the financial bottleneck in demand side management (DSM) in China", Energy Policy, 38 (10), pp. 6101-6110

97. Yu, Y. (2012) "How to fit demand side management (DSM) into current Chinese electricity system reform?", Energy Economics, 34 (2), pp. 549-557

98. Yun, J. and Price, L. (2011) "Voluntary energy efficiency agreements in China: history, impact, and future", ECEEE Summer Study 2013 Proceedings, European Council for an Energy-Efficient Economy (ECEEE)

99. Zarnikau, J.W. (2010) "Demand participation in the restructured Electric Reliability Council of Texas market", Energy, 35 (4), pp. 1536-1543

100. Zheng, N., Zhou, N., Fino-Chen, C. and Fridley, D. (2012) "Evaluation of local enforcement of energy efficiency standards and labeling program in China", International Energy Program Evaluation Conference 2012

101. Zhou, N., Mcneil, M. and Levine, M. (2011) "Assessment of Building Energy-Saving Policies and Programs in China during the 11th Five Year Plan", Ernest Orlando Lawrence Berkeley National Laboratory, USA 
102. Zuckerman, J., Deason, J. and Chandrasehkeran, S. (2013) "Rewarding efficiency: lessons from California's shareholder incentives", International Energy Program Evaluation Conference 2013 